\title{
ANTROPOCENO + CAPITALOCENO
}

\author{
Jorge Riechmann
}

Universidad Autónoma de Madrid 



\section{UNA «FUERZA GEOLÓGICA PLANETARIA»}

La capacidad de impacto ambiental de los grupos humanos ha aumentado tremendamente desde los comienzos de la Revolución Industrial, y muy en especial durante el período llamado «fordista» del capitalismo (a partir de 1930-1950). Desde mediados del siglo Xx, la expansión del sistema socioeconómico se acelera hasta convertirse en un proceso básicamente fuera de control: tiene todo el sentido hablar aquí de "Gran Aceleración». Hasta tal punto es así que no resulta exagerado afirmar junto con el químico y biólogo ruso Vladimir Vernadsky (1863-1945), uno de los fundadores de la ecología científica ${ }^{1}$, que «el ser humano se ha convertido en una fuerza geológica planetaria» (Vernadsky 1945, reimpreso en Vernadsky 1997: 216): tal es la dimensión que ha alcanzado su capacidad de alterar la biosfera dentro de la cual y gracias a la cual vive, incluyendo los grandes ciclos bioquímicos y fisio-geológicos del planeta.

\section{INTENSIFICACIÓN: UN GIGANTE DE 25 KM DE ESTATURA}

Cabe visualizar esta enorme y aún creciente capacidad de impacto global mediante un concepto que permite expresar de forma sintética distintas dimensiones del impacto ambiental: el de intensificación. La intensificación expresa

\footnotetext{
${ }^{1}$ Vernadsky es el gran teorizador de la biosfera como fenómeno terrestre global: desarrolla una comprensión biosférica como ecología planetaria. Como subrayó Ramón Margalef, «anticipa la visión global de la biosfera como una entidad funcional unificada, con las propiedades y capacidades sintéticas que ahora se propugnan y compendian bajo la imagen de Gaia, en una forma divulgada principalmente por James E. Lovelock» (introducción a Vernadsky 1997: 11).
} 
cómo aumenta dentro de un territorio limitado el flujo de energía canalizado por los seres humanos en su propio beneficio y es un buen indicador del impacto ambiental producido por las actividades humanas.

La entrada del hombre en este escenario podría ser relativamente discreta -una especie más, omnívora y con capacidad de comer casi cualquier cosa que no sea hierba verdepero no ha sido así, ni siquiera en el caso de las sociedades de cazadores-recolectores. La intensificación expresa la capacidad de las culturas humanas de encauzar de manera cada vez más decidida los flujos de energía presentes en un territorio determinado hacia el crecimiento de su propia biomasa. [...] En sucesivos escalones de la intensificación, los humanos pueden sustituir los ecosistemas naturales casi por completo, canalizando la energía solar a través de unas pocas especies de plantas cultivadas y de animales domésticos. [...] Como consecuencia de la intensificación, la biodiversidad se reduce drásticamente, la producción de materia orgánica aprovechable crece en relación con la que se almacena como biomasa, se establecen intensos flujos de transporte horizontal -pues los productos obtenidos deben ser llevados a sus puntos de consumo- y, por último, los circuitos cerrados de reciclaje de materiales se rompen; se producen indeseables acumulaciones de residuos en algunos puntos que exceden la capacidad de asimilación natural, o que incluso son tóxicos para los seres vivos. (Alonso Millán 1995: 12-13)

La densidad de población de los cazadores-recolectores que poblaron la Península Ibérica hace unos diez mil años no superaba probablemente el habitante por kilómetro cuadrado en las zonas más favorables, es decir, una población total de medio millón de habitantes, calculando muy por lo alto ${ }^{2}$. A finales del siglo XX, después de un impresionante proceso de intensificación, habitábamos en el mismo territorio unos 50 millones de personas: la población se había multiplicado por cien.

\footnotetext{
2 La población humana en todo el planeta, antes de la Revolución Neolítica (hace unos diez mil años), no superaba los cuatro millones. En el 2000 a.C. ascendía a 27 millones y alcanzó los cien millones a comienzos de la era cristiana.
} 
Pero si la población se ha multiplicado por cien, en la Península Ibérica podemos estimar que el impacto humano sobre el medio ambiente (asociado con el proceso de intensificación) se ha multiplicado por 10000 en los últimos 10000 $a_{n} o^{3}$. En términos de flujos de energía: hace 10000 años, cada uno de los aproximadamente 500000 cazadores-recolectores que habitaban la Península consumía la energía equivalente a unos $30 \mathrm{~kg}$ de carbón al año (no incluimos en la cuenta la energía proporcionada por los alimentos, que equivale a unos 100 watios diarios). Echando cuentas, a finales del siglo XX, con 50 millones de habitantes poblando el mismo territorio, cada uno de estos hispanoportugueses industrializados tiene un consumo energético medio de tres toneladas de equivalente de carbón por persona cada año, es decir, unas 300 toneladas de equivalente de carbón por $\mathrm{km}^{2}$ y año (Alonso Millán 1995: 31).

Podemos visualizar esta situación de la manera siguiente: si al cazador-recolector ibérico de hace diez mil años, que caminaba ligeramente sobre la tierra, le asignamos una estatura «normal» de 1'60 metros, «el lusoespañol industrializado de finales del siglo XX sería un gigantón de 16 km de estatura», y su huella sobre el territorio y los ecosistemas sería un pisotón proporcional a esta desproporción. Actualizando este cálculo de Jesús Alonso Millán, nuestro gigante habría crecido aún más: pues en España pasamos de un consumo de energía primaria de unos 100 Mtep (millones de toneladas de equivalente de petróleo) en 1995 a 160 Mtep en 2007 (antes de descender el consumo a consecuencia de la crisis económica que se inició en 2008; datos del BP Statistical Review of World Energy 2013). Nuestro gigante mediría «casi 25 km» a comienzos del siglo XXI. Es sin duda una imagen que impresiona.

\footnotetext{
3 Este somero cálculo referido a la Península Ibérica nos desvela ya la falsedad que supone identificar el crecimiento demográfico como el esencial factor de presión sobre los recursos naturales y causa de deterioro ecológico. Poblaciones de idéntica cuantía pueden tener impactos ambientales sumamente desiguales, en función de sus diferentes pautas de producción y consumo. Por ejemplo, el investigador del Worldwatch Institute Alan Durning ha estimado que en promedio la población de los países sobredesarrollados del Norte consume 10 veces más energía per cápita que la población del Sur; 19 veces más aluminio, 14 veces más papel, 10 veces más madera, 6 veces más carne, 5 veces más fertilizantes y 3 veces más cereales.
} 


\section{EL ANTROPOCENO}

A partir de intuiciones como la de Vernadsky, a finales del siglo XX se formula la noción de «Antropoceno». El término procede del químico holandés Paul J. Crutzen (junto a Eugene F. Stoermer), ganador en 1995 del Premio Nobel de su especialidad por sus aportaciones a la química del ozono en la atmósfera terrestre. El Antropoceno sería la era en la que el impacto conjunto de la humanidad en la Tierra iguala o sobrepasa el poder de las fuerzas naturales (geológicas y biológicas) (Crutzen / Stoermer 2000; Steffen et al. 2011; síntesis de datos y análisis en Fernández Durán 2011).

¿Cuándo habría comenzado esta era geológica, que se postula como la siguiente al Holoceno? Puede que la propuesta más sólida sea considerar la fecha de la detonación de la primera bomba atómica, en el desierto de Nuevo México el 16 de julio de 1945, como principio del Antropoceno. Los elementos radiactivos depositados en los sedimentos a raíz de aquella y sucesivas explosiones (una cada 9,6 días hasta 1988) tienen un origen inequívocamente humano, como lo tienen los plásticos que se depositan en los fondos marinos (Zalasiewicz et al. 2014). Así, en términos geológicos muy simples, el Antropoceno sería «la Edad del Plutonio».

Hoy las pruebas se amontonan: extinción de flora y fauna, micropartículas de plástico y aluminio en sedimentos oceánicos, depósitos masivos de nitrógeno y fósforo de uso agrícola que alteran los ciclos químicos básicos, los indicios radiactivos de las detonaciones de bombas nucleares desde 1945 hasta el final de las pruebas atómicas de superficie en los años sesenta y, por supuesto, el dióxido de carbono como principal de los gases de «efecto invernadero». En los años cincuenta, el $\mathrm{CO}_{2}$ en la atmósfera se medía en 315 partes por millón (ppm), superando las $280 \mathrm{ppm}$, la media aproximada a lo largo de los últimos 5000 años. En 2016 llegó a las 400 ppm y sigue creciendo. En definitiva, los geólogos tienen buenas razones para fechar el Antropoceno alrededor de 1945 (Waters et al. 2016). 


\section{LA GRAN ACELERACIÓN}

A mediados del siglo XX habría tenido lugar, según Will Steffen, la transición efectiva del Holoceno al Antropoceno en forma de "Gran Aceleración» ${ }^{4}$. El Holoceno es el periodo de la historia geológica del planeta Tierra, dentro del Cuaternario, en el que nos hallábamos desde hace algo más de diez mil años. Ahora bien, «la segunda mitad del siglo XX es única en toda la historia de la existencia humana en la Tierra. Muchas actividades humanas llegaron a puntos de despegue en algún momento del siglo xx y se han acelerado bruscamente hacia el final del siglo. Los últimos cincuenta años del siglo XX [y lo que llevamos del siglo XXI, J.R.] han visto sin duda la más rápida transformación de la relación humana con el mundo natural de toda la historia de la humanidad» (Steffen et al. 2015). «Es difícil sobreestimar la magnitud y la velocidad del cambio. En una sola vida la humanidad se ha convertido en una fuerza geológica a escala planetaria», señala el autor principal, Will Steffen, de la Universidad Nacional de Australia y el Centro de Resiliencia de Estocolmo. Los investigadores e investigadoras han trazado gráficos de la actividad humana desde el comienzo de la Revolución Industrial (hacia 1750) al año 2010 así como de los cambios en el sistema de la Tierra en este período: los niveles de gases de efecto invernadero, la acidificación de los océanos, la desforestación, el deterioro de la biodiversidad... Doce indicadores muestran la actividad humana, entre ellos el crecimiento económico (PIB), la población, el uso de energía, las telecomunicaciones, el transporte y el uso del agua. Otros doce, los cambios ambientales: en el ciclo del carbono, el ciclo del nitrógeno, la biodiversidad... «La primera vez que agregamos estos datos, esperábamos ver grandes cambios, pero lo que nos sorprendió

\footnotetext{
4 Señala con acierto Josep Xercavins que es mejor hablar de Gran Aceleración que usar el eufemismo "cambio global»: «la exponencialidad tan manifiesta de todas (jtodas!) las tendencias presentadas, actualizadas y analizadas [muestra] que todos nuestros sistemas: sociales, económicos, ambientales, etc. están claramente acelerándose -evolucionan con el tiempo de forma exponencial: con una gran aceleración-y están, por lo tanto, fuera -totalmente fuera- de toda tendencia lineal mínimamente estabilizadora, mínimamente cercana a futuras situaciones estacionarias» (Xercavins 2015).
} 
fue el tiempo. Casi todas las gráficas muestran el mismo patrón. Los cambios más dramáticos han ocurrido a partir de 1950. Fue el inicio de la 'Gran Aceleración'», dice Steffen (De Jorge 2015).

La Gran Aceleración ha conducido a resultados tan estupefacientes como que la mitad de los combustibles fósiles y muchos otros recursos utilizados por los seres humanos «los hemos consumido apenas en los últimos cuarenta años» (Rees 2017) -y encima con la distribución brutalmente desigual que es bien conocida. Los crecimientos exponenciales incrementan «exponencialmente» la gravedad de los problemas. Que nos permitamos ignorar algo tan obvio resulta demencial.

Sintetiza Mateo Aguado:

La Gran Aceleración es como se conoce al fenómeno de rápidas transformaciones socioeconómicas y biofísicas que se inició a partir de mediados del siglo XX como consecuencia del enorme desarrollo tecnológico [y económico] acontecido tras el final de la Segunda Guerra Mundial. Según sus defensores (Crutzen y Stoermer, 2000; Steffen et al., 2011, 2015), este fenómeno, junto a la posterior globalización económica, habría sumido al planeta Tierra en un nuevo estado de cambios drásticos inequívocamente atribuible a las actividades humanas. Así, el enorme crecimiento del sistema económico-financiero mundial, junto al desarrollo tecnológico y al proceso de globalización, habrían posibilitado un acoplamiento a escala planetaria entre el sistema socioeconómico y el sistema biofísico de la Tierra que representaría el comienzo de la era de los humanos. (Aguado 2016a: 17)

\section{5. ¿POR QUÉ EL ANTROPOCENO ES TAN SEXY -EN TÉRMINOS MEDIÁTICOS?}

¿Por qué la noción de Antropoceno ha recibido, desde su mismo surgimiento, una enorme atención mediática -mientras que, por lo general, el trabajo de los 
geólogos suele pasar inadvertido para el gran público? Seguramente una de las razones que explican tanto interés es que, entendida de cierta forma, la idea de Antropoceno «alimenta la ideología del exencionalismo humano» 5 . La cultura dominante nos induce a pensarnos como algo aparte de la naturaleza, superior a ella; y casi se podría decir que estamos enamorados de nosotros mismos -incluso cabría hablar de "narcisismo de especie». Pero eso forma parte de nuestro fenomenal problema actual, ese que situamos bajo el signo de una «crisis ecológico-social de alcance planetario».

Abrigamos la fantasía de que, aunque la Tierra se vaya al carajo, nosotros seguiremos ahí... Es justo al revés: la vida seguirá adelante (es extremadamente resiliente) aunque nosotros desaparezcamos. Como señaló en muchas ocasiones la gran Lynn Margulis, el Homo sapiens es peligroso para sí mismo (y para muchas otras especies), pero no para Gaia ${ }^{6}$.

\footnotetext{
5 Señala Ernest García que nos conviene distinguir entre exencionalismo y excepcionalismo. La primera de estas dos creencias «consiste en pensar que las leyes de la física y la biología no condicionan la organización y el cambio de las sociedades, que -por decirlo así- dichas leyes dejan de regir cuando se trata de los asuntos humanos. La segunda, por su parte, puede llamarse 'excepcionalismo' y nos remite a la emergencia de novedades en la organización que no son observables en otros niveles de la realidad. [...] La existencia social contiene numerosas excepciones; ninguna de ellas, sin embargo, nos exime de la ley de la entropía ni de la programación genética de algunos comportamientos» (García 2004: 35). Pueden rastrearse estas nociones hasta Catton y Dunlap 1978.

6 Hace tiempo que la «hipótesis Gaia» se convirtió en la «teoría Gaia»: nuestro medio ambiente planetario es homeostático. El sistema de la Tierra se autorregula, tendiendo a mantener constantes su temperatura y composición atmosférica. James E. Lovelock lo comprendió en los años setenta del siglo XX, y desde entonces hemos ido entendiendo cada vez más de la inmensa complejidad de estos mecanismos de autorregulación, y del papel crucial de los seres vivos en ello (Lovelock 1986; Thompson 1989). "La teoría Gaia está basada en una simple idea: los seres vivos influyen en su entorno, no sólo se adaptan a él. El conjunto de los seres vivos o biota tiene tanta importancia en el entorno global o biosfera que se abre la puerta a la idea de coevolución y regulación del ambiente por parte del conjunto de los vivientes, y juntos, ambiente y seres vivos, hacen al sistema global como si de una entidad vida se tratara» (De Castro 2008: 175). Deberíamos comprender el carácter excepcional de nuestra Madre Tierra, Gaia/ Gea, con sus impresionantes capacidades de autorregulación basada en la vida y favorable a la vida. La biosfera en la geosfera de nuestro tercer planeta del sistema solar constituye un gran supersistema homeostático: la comparación con la tórrida Venus y el helado Marte, desprovistos de vida, debería enseñarnos «temor y temblor».
} 
Gaia, una perra vieja, no está en absoluto siendo amenazada por los humanos. La vida planetaria sobrevivió por lo menos tres mil millones de años antes de que la humanidad fuera siquiera el sueño de un simio lúcido que deseaba una compañera sin pelo. Necesitamos honestidad. Necesitamos que nos liberen de nuestra arrogancia especie-centrista. [...] No somos los más importantes porque seamos tan numerosos, poderosos y peligrosos. Nuestra tenaz ilusión de poseer una patente de corso oculta nuestro verdadero estatus de mamíferos erectos y enclenques. (Margulis 2002: 140-141)

Nada de exencionalismo: somos interdependientes y ecodependientes (Riechmann 2012).

\section{EL APRENDIZ DE BRUJO}

En el Antropoceno, entonces, los cambios inducidos por la actividad humana (antropogénicos) pondrían fin a unos 12000 años de variabilidad natural del anterior Holoceno. Antropoceno, ciertamente, es una categoría útil («la unidad geocronológica y cronoestratigráfica bajo la cual tiene lugar el proceso antropogénico del Cambio Global. O, dicho de otra forma, la unidad de tiempo geológico bajo la cual los seres humanos estaríamos modificando con nuestras acciones los patrones o ritmos naturales de cambio de la ecosfera, sacando con ello al planeta de su 'variabilidad natural'», Aguado 2016b); pero -en mi opiniónla referencia no sería aquí un anthropos todopoderoso que controle eficazmente la biosfera, sino más bien un imprudente aprendiz de brujo a quien la escoba se le escapa de las manos...

Escribía el oceanógrafo Carlos Duarte: «Las características específicas del cambio global [1. rapidísimo, 2. antropogénico] han llevado a proponer el término Antropoceno para referirse a la etapa actual del planeta Tierra. Es un término propuesto [...] para designar una nueva era geológica en la que la humanidad 
ha emergido como una nueva fuerza capaz de controlar los procesos fundamentales de la biosfera» (Duarte 2006: 24). Pero ¿de verdad cabe imaginar que controlamos los procesos fundamentales de la biosfera?

Antropoceno no quiere decir que «la Tierra se rige cada vez más por las leyes y los deseos del hombre» (Prat 2017: 42), como nos figuramos a menudo, borrachos de nuestra ilusión de control. Interferimos en casi todos los procesos naturales; apenas controlamos ninguno. Por no controlar, ni siquiera controlamos procesos sociales básicos -como el crecimiento de las ciudades o las guerras. Como bien puntualiza el «mirmecólogo en jefe» del planeta Tierra, Edward O. Wilson,

el control de la humanidad sobre el planeta carece de fuerza, es cada vez más débil. La población es demasiado numerosa para gozar de seguridad y comodidad. El agua dulce escasea, la atmósfera y los mares están cada vez más contaminados [...]. Como nos creemos los soberanos de la biosfera y su resultado supremo, consideramos que tenemos derecho a hacer lo que queramos con las demás formas de vida [...]. [Pero] aún somos organismos absolutamente dependientes de otros organismos. [...] La biodiversidad en su conjunto forma un escudo protector para las especies que la componen, incluyéndonos a nosotros. [...] Los seres humanos no están exentos de la ley férrea de la interdependencia de las especies. La biosfera no nos pertenece, somos nosotros quienes le pertenecemos a ella. (Wilson 2017: 12, 26, 27, 29 y 32)

En el mismo sentido advierte Kohei Saito que

aunque el impacto de la humanidad sobre la tierra ha llegado a ser sumamente omniabarcador y poderoso hoy en día, su utopía moderna de realizar el absoluto dominio sobre la naturaleza no se ha llevado a cabo. Por el contrario, suena más razonable argumentar que el Antropoceno está caracterizado por un fracaso definitivo de este proyecto moderno. El calentamiento global, la desertificación, la extinción masiva de las especies, la 
catástrofe nuclear en Chernobyl y Fukushima son todas características de la actual crisis ecológica, y amenazan al planeta con desastres ecológicos incontrolables. (Saito 2017) ${ }^{7}$

\section{Hemos de distinguir cuidadosamente entre Antropoceno como necesaria} categoría científica (geológica, estratigráfica) y la ideología antropocénica (ebria de ilusión de control sobre la naturaleza) que florece en nuestros días... ${ }^{8}$. Por lo demás, si prosiguen las destructivas tendencias en curso, especialmente la sexta gran extinción, el Antropoceno puede convertirse en «el Eremoceno, la edad de la soledad. El Eremoceno es básicamente la era de la gente, de las plantas y animales domésticos, de los campos de cultivo extendidos hasta donde la vista alcanza a lo largo de todo el mundo» (Wilson 2017: 36) ${ }^{9}$. Una edad que se derrumbaría pronto, socavada por sus desequilibrios intrínsecos.

\footnotetext{
7 Este investigador ecomarxista afirma a continuación: «La dialéctica de la Ilustración, con su particular consideración hacia el dominio de la naturaleza, está operando aquí: un enorme desarrollo de las fuerzas productivas, las cuales permiten a los humanos transformar la totalidad de la Tierra sin dejar ninguna parte incólume, hacen al mismo tiempo prácticamente imposible organizar una producción social sostenible. Tanto la producción como el consumo en masa bajo la competición anárquica entre los individuos atomizados modernos socavan sus condiciones materiales de existencia. Esta dialéctica de la Ilustración, la cual comienza con la muerte de la naturaleza (Merchant 1990) arroja ahora una sombra oscura sobre el futuro del Antropoceno».

8 Interesante reflexión crítica sobre esta última (la ideología antropocénica) en Wilson 2017. Wilson es muy bueno cuando escribe sobre biología, pero desbarra cuando llega a la economía y la tecnología, p. 255 y ss. Casi un caso clínico para estudiar la olla podrida ideológica en la que nadamos. Sin analizar el capitalismo, no entenderemos apenas nada de la sexta extinción...

9 Un cálculo de la biomasa (en peso) de los mamíferos terrestres hoy existentes arroja el resultado siguiente: humanos + ganado y mascotas, 97,11\%; seres silvestres, 2,89\%. Los seres humanos representamos el $30,45 \%$... Más de diez veces lo que suponen los mamíferos salvajes. Los datos proceden de la conferencia de Richard Register en la mesa redonda «¿Nuevo clima, nuevo modelo de desarrollo?», en el Encuentro de las Américas Frente al Cambio Climático, organizado por la Alcaldía Mayor de Bogotá y otras instituciones colombianas, Bogotá, 20 a 23 de septiembre de 2015.

Pero vivimos de espaldas a esa realidad, sumidos en nuestra burbuja cultural, como vivimos de espaldas a tantas otras realidades básicas... Cuando en charlas y debates he pedido a la audiencia que estimaran el porcentaje de esa biomasa de seres silvestres, las estimaciones oscilaban entre $20 \%$ y 70 \%. jAsí de alejadas están nuestras percepciones de la realidad!

Hay en el mundo, hoy, unos 900000 búfalos africanos... frente a 1500 millones de vacas. 200000 lobos... y más de 400 millones de perros domésticos. 50 millones de pingüinos... y 20000 millones de gallinas (Harari 2016: 87). La pregunta de justicia que hemos de hacernos es: ¿por qué una sola especie se arroga el derecho de tratar así a todas las demás? ¿Cómo se nos ocurre que tenemos derecho a ocuparlo todo, a acapararlo todo?
} 
Hay que insistir sobre ello: interferencia humana no significa control. Interferimos en casi todo en la naturaleza, no controlamos casi nada (ipensemos en el calentamiento global!). Para empezar, ni siquiera somos capaces de controlarnos a nosotros mismos... ${ }^{10}$. Así, cuando por ejemplo alguien escribe que «la historia nos ha enseñado una y otra vez que los seres humanos continuarán ejerciendo su impulso de transformar y controlar la naturaleza» (Schmitz 2016, cap. 1), hay que insistir: trasformar es una cosa; controlar, otra bien distinta. El concepto «Antropoceno» debería remitirnos no a un mundo dominado, sino a un mundo desquiciado.

\section{EL CAPITALOCENO}

Desde las ciencias humanas y sociales, y la filosofía, se ha desarrollado -en el segundo decenio del siglo XXI- una importante crítica de la noción de Antropoceno (Bonneuil / Fressoz 2013; Malm 2015). Se le reprocha un efecto despolitizador y des-responsabilizador, por generalizar y homogeneizar los efectos de la acción humana sobre la Tierra. Hemos de preguntarnos: ¿quién es responsable de qué? Los movimientos de justicia climática, por ejemplo, critican las «narrativas del Antropoceno» por sustentar la idea de responsabilidades iguales entre pueblos, regiones, géneros y clases sociales. Pero los responsables del cambio climático no son todos los seres humanos, sino aquellos que han producido más GEI (gases de «efecto invernadero»)... Puede constatarse que, en 2015, la mitad de las emisiones totales de dióxido de carbono (el principal de los GEI)

\footnotetext{
10 Tenemos un problema masivo de hybris del aprendiz de brujo. Necesitaríamos una «ecología de la mente», como reclamaba el sabio Gregory Bateson: una ecosofía - de la que colectivamente parecemos incapaces... La idea de dominación humana sobre la naturaleza tiene algo de irrisorio. El simio averiado que somos, ¿dominador de la naturaleza? Fantasías nietzscheanas de Übermensch, que serían cómicas si no estuviésemos fraguando una verdadera catástrofe.

Pero esa interferencia masiva del Antropoceno es muy real. Los poderes del desatinado aprendiz de brujo son reales. De ahí nuestras responsabilidades especiales -no somos animales como los demás...
} 
fue responsabilidad de apenas 700 millones de personas, el $10 \%$ de la población más rica; mientras que la mitad de la población mundial -3500 millones- generó el $10 \%$ de las emisiones de GEI (Cano Ramírez 2017: 9) ${ }^{11}$. No debería ocultarse que el cambio climático está profundamente unido a la desigualdad económica: se trata de una crisis impulsada por las emisiones de GEI generadas por los ricos, pero que afecta fundamentalmente a los más pobres y desprotegidos. $\mathrm{Y}$, en términos de agentes históricos, el principal emisor de $\mathrm{CO}_{2}$ a la atmósfera es el ejército de EE. UU. (De Soto 2017: 113)... Pero a los ricos

les ha costado reconocerlo y rechazan su deuda ecológica. De igual manera, la humanidad está llevando a una sexta extinción masiva a la gran mayoría de las especies del planeta. La primera gran extinción causada por los humanos. Pero no todos los humanos participan por igual. También la humanidad amenaza con sobrepasar otros límites planetarios de sostenibilidad hasta llegar a un colapso ambiental global. Estas afirmaciones crean una narrativa en la que el ser humano es ese ser voraz, insaciable en su codicia, destructor nato del medio ambiente e incapaz de vivir en armonía con la naturaleza. El discurso es totalizante: el ser humano, la humanidad en su totalidad, ha llevado a la Tierra a esta crisis; sobre todos los humanos pesa entonces este yugo. Hay que cargar con un peso existencial superior al de Atlas frente a la gran culpa del insaciable Homo esophagus colossus o ecocida, destructor de mundos... (Fernández Carril / Cardoso / Marcellesi 2017: 6)

Jason W. Moore es uno de los autores que ha desarrollado con mayor profundidad teórica esta crítica (Moore 2015, 2016). En una entrevista declara:

El otro argumento, que es el que ha ganado tanta popularidad, consiste en reconfigurar la historia del mundo moderno como la edad del hombre, «el Antropoceno». Este es un viejo truco capitalista: decir que los problemas del mundo son los problemas creados por

\footnotetext{
${ }^{11}$ A partir de cálculos de Oxfam, que además indican que las emisiones de GEI del $1 \%$ más rico son 30 veces mayores que las del $50 \%$ más pobre y superan 175 veces las del $10 \%$ más pobre de la población mundial (Oxfam 2015)
} 
todos, cuando en realidad han sido creados por el capital. Y es por esto que creo que deberíamos hablar del Capitaloceno, como una era histórica dominada por el capital. Si nos fijamos en el periodo que va de 1450 a 1750, vemos una revolución en la producción del medio ambiente (environment-making revolution) sin precedentes desde la revolución neolítica, con el amanecer de las primeras ciudades. Esa revolución estuvo marcada (e incrementada en escala, alcance y velocidad) por el cambio ambiental que emanó del capitalismo atlántico-céntrico. Una transformación de paisajes y ambientes muy rápida que afectó una región del planeta tras otra. En estos siglos vemos no solo una nueva dominancia de la producción e intercambio de mercancías en la transformación del ambiente global, sino también nuevas formas de ver y entender la naturaleza con mayúscula -es decir, la Naturaleza como algo «ahí fuera», fuera de la sociedad, pero que incluye mucha gente no blanca, muchas mujeres, quizás incluso la mayor parte de la humanidad-. El Capitaloceno en sentido amplio va más allá de la máquina de vapor y entiende que el primer paso en esta industrialización radical del mundo empezó con la transformación del medio ambiente global en una fuerza de producción para crear algo a lo que llamamos la economía moderna y que es mucho más grande de lo que puede contener el término economía. (Moore 2017: 109)

En el cruce de relatos en torno al Antropoceno que pugnan por dar sentido al mundo en que estamos viviendo, hay quien distingue ya, al menos, los cinco siguientes: el relato naturalista del poder de la ciencia, el relato ecopragmático (o ecomodernista) de la muerte de la naturaleza, el relato ecocatrastrofista, el relato ecomarxista y el relato ecofeminista (Herrero 2017: 22-23). Al menos los tres últimos son, de forma nítida, relatos críticos con el productivismo / consumismo / extractivismo que nos ha llevado al borde del abismo donde hoy nos encontramos.

Desde la izquierda (que podemos entender en sentido amplio como la gente comprometida con el valor central de la «igualibertad») ${ }^{12}$, por tanto, se

\footnotetext{
12 Étienne Balibar fusionó los valores de igualdad y libertad en el término único de égaliberté («igualiber-
} tad»). Véase Balibar 1990. 
alzan voces críticas que advierten: no habléis de Antropoceno, es el Capitaloceno (y quizá también el Faloceno). La noción de Antropoceno «se erige como un obstáculo para cambiar el modelo de dominio humano, ya que mantiene la ilusoria partición entre los seres humanos y la naturaleza, sustenta una noción esencialista de nuestra especie, sobrevalora los efectos de la actividad humana en el planeta y es un concepto que impide formular otros futuros» (LaDanta LasCanta 2017: 27). Y se rechaza explícitamente que la «naturaleza humana» pueda aparecer como factor explicativo en este debate (Cano Ramírez 2017: 8).

Ahora bien: quizá es que nos da miedo mirar a los ojos al simio averiado que somos. Resulta sin duda desalentador, mas ¿no pudiera ocurrir que, además de padecer un brutal problema socioeconómico, tuviésemos un fenomenal problema antropológico?

\section{DESPLAZAMIENTOS DE LA GRAN AMEBA}

Por si no fuera bastante con el capitalismo..., todo indica que también tenemos graves problemas con la naturaleza humana. Una sociedad poscapitalista tendría que seguir lidiando con problemas de sustentabilidad. ¿Podemos ser para la biosfera algo distinto a lo que es una plaga de langostas para un campo de cereal? Esa perturbadora pregunta, por mucho sosteniblablá que nos gastemos (Engelman 2013), está aún por contestar.

El ensayista estadounidense Nate Hagens, antaño profesional de elevada posición en Wall Street y hoy ecologista experto en energía, ha propuesto una perturbadora pero acertada imagen del «superorganismo humano» como Gran Ameba. «El superorganismo (al que aquí llamaré cariñosamente la Ameba) no piensa; utilizando el excedente financiero optimizado por el mercado, avanza deslizándose, absorbiendo a los majetes que viven con baja entropía, mirando 


\section{exclusivamente a corto plazo el camino que se encuentra justo enfrente; y solo cambia el rumbo cuando puede recolectar más» ${ }^{13}$.}

\footnotetext{
${ }^{13}$ Continúa así su reflexión: «Esta recolección, cuando se suman los 7300 millones de 'votos', termina buscando energía bruta que quemar y la transfiere a unos pocos micro-litros de neurotransmisores. La Ameba no piensa en energía neta porque está más allá de su horizonte visual (aunque últimamente reconoce con cierta dificultad que algo no está yendo bien). Y a la Ameba, desde luego, no le preocupan lo más mínimo las externalidades. No puede verlas, a menos que le bloqueen el camino de acceso a la recolección de baja entropía.
}

La Ameba terrestre se encontró en su camino con algunos baches en los años 70 del siglo XX. La Tasa de Retorno Energético (TRE) llegó a un máximo y comenzó a disminuir. Los problemas del sistema monetario obligaron a Nixon a salirse del patrón oro y desde ese momento en adelante no existe una moneda en la Tierra que tenga un recurso natural vinculado a ella, y todo el dinero se crea de la nada; el $95 \%$ aproximadamente a través de créditos bancarios comerciales, que siguen la misma regla en todos los países.

Comenzamos entonces con la globalización, para dedicar a las dendritas de la Ameba a succionar entropía de las regiones geográficas con menor coste. Aprovechamos la tecnología para construir una máquina térmica más grande. Y lo más importante (y peligroso), comenzamos a utilizar la deuda y el crédito como formas de traernos los recursos futuros hacia el presente. Nada de esto se hizo de forma consciente: fue una simple reacción a los deseos y necesidades de las masas en cada tiempo, para seguir funcionando a base de ir agregando los beneficios optimizados de las mini-amebas. [Esta parte de la narración de Hagens es la que hay que cuestionar, claro está... No han sido "los deseos y necesidades de las masas", sino las opciones de la clase dominante y el mecanismo autoexpansivo de la acumulación de capital. Pero sigamos.] Cada vez que una espita energética se va cerrando, surgen nuevas reglas o inyecciones monetarias que suavizan la trayectoria. En las primeras etapas, todavía existía una carrera armamentística entre la energía y el dinero. En 2008 quedó claro que los bancos comerciales y los mercados del crédito privado ya no podían seguir alimentando adecuadamente a la Ameba. Por tanto, se saltaron la jerarquía y comenzaron a gestionar directamente y a la vista de todos el acceso a la espita monetaria, que llegaron a abrir de forma considerable. En un momento en el que el coste real del capital (el petróleo) estaba aumentando, se inundó el mundo de créditos a bajo interés, convirtiendo el dinero en algo prácticamente gratuito.

Pero crearon demasiado y el gran cuerpo se vio imposibilitado de generar algún tipo de crecimiento con sentido y ahora nos encontramos en un pulso deflacionario preliminar. En la actualidad, aproximadamente un $30 \%$ de los bonos de los gobiernos del mundo tienen rendimientos negativos y alrededor del $90 \%$ tienen rendimientos inferiores al $2 \%$. Las entidades gubernamentales de los gobiernos de Japón y Europa están comprando bonos a un ritmo tal que en el plazo de diez años les darán la propiedad completa de todos los bonos emitidos (los gobiernos están comprando dinero para comprar bienes que requieren energía y, por tanto, también están garantizando -y comprando- los mismos bonos en el mercado abierto).

El mayor supuesto falso sobre el que se apoya la sociedad moderna es que el dinero y la energía son intercambiables y que todos los dólares pasados, presentes y futuros (o yenes o euros, etc.) son iguales y se convertirán en los bienes que el dinero representa. [...] Estamos ahora en una situación en la que la OCDE (descontando los derivados financieros, que son en su mayoría simplemente hipotéticos y no suponen reclamaciones sobre activos físicos) tiene unos 300 billones de dólares de lo que 'la gente cree que posee' en términos de stocks, bonos, depósitos, dinero, etc. de la OCDE, frente a los 80 billones de lo que se denominan 'ingresos' del PIB mundial anual. Es el mayor esquema de estafa piramidal (esquema Ponzi) que jamás se haya visto en este (u otro) planeta» (Hagens 2016). 
La Gran Ameba adelanta un pseudópodo para apoderarse del siguiente yacimiento de exergía (o materia-energía de baja entropía). Quizá podría emitir igualmente un pseudópodo que se volviese sobre ella misma, tornándose reflexiva (ah, la suprema importancia de los bucles de realimentación...). Pero lo segundo exige mucho más esfuerzo. Si la Gran Ameba se deja caer por su pendiente deslizante (llamémoslo Maximum Power Principle) ${ }^{14}$, emitirá pseudópodos de la primera especie.

$Y$, en efecto, así parece comportarse el superorganismo humano en casi todas las circunstancias... ${ }^{15}$. Y así nos va. El contenido teórico de la imagen de la humanidad como plaga, más allá de lo metafórico, ha sido reivindicado desde hace tiempo. Así, Reg Morrison sostiene que la mayor parte del daño causado a la biosfera es el inevitable producto de la sobrepoblación humana, así como una parte necesaria del ciclo de una plaga (Morrison 1999: 241-242, sintetizado en García 2006: 37). Y, sobre bases más sólidas, William Rees ha argumentado que para comprender la insostenibilidad de la trayectoria de nuestra especie hay que tener en cuenta factores biológicos - de naturaleza humana- y no

${ }^{14} \mathrm{El}$ «Maximum Power Principle», intuido por diversos biólogos desde tiempos de Lotka, fue enunciado por Howard T. Odum en estos términos: «Durante la auto-organización, se desarrollan y prevalecen diseños de sistemas que maximizan el consumo de energía y su transformación, así como aquellos usos que refuerzan la producción y la eficiencia», leemos en la Wikipedia (https://en.wikipedia.org/wiki/Maximum_power_ principle; trad. mía, JR). Desde la biología evolucionista se ha sugerido también una importante Constructal Law (https://en.wikipedia.org/wiki/Constructal_law).

"Todos queremos más», enseña una canción de la que se han hecho múltiples versiones (hay una, por ejemplo, de Peret). El «Maximum Power Principle» viene a ser el «todos queremos más» elevado a rango de conjetura científica de alto nivel. El gran desafío es vencer esa conventional wisdom y ser capaces de afirmar: lo suficiente basta.

15 «Muchos de nosotros, si decidiéramos individualmente, no hay duda de que elegiríamos la vía de la moderación. Y si fueran grupos pequeños y cohesionados, probablemente mucho más. Pero la tragedia es que en este mundo enorme y fragmentado en el que vivimos no existe nada parecido a una sabiduría colectiva, y en lugar de comportarnos como un superorganismo inteligente nos comportamos como las bacterias en una placa de Petri o las levaduras en un tanque de fermentación. ¿Existe solución a esta situación? Quisiera pensar que sí. De hecho somos muchos y muchas quienes pensamos que sí, a pesar de las enormes dificultades, y nos negamos a arrojar la toalla. Y espero que seamos cada vez más...» (Barba 2017). Reflexión adicional de Nate Hagens sobre la Gran Ameba en http://tratarde.org/presentaciones-del-simposio-de-la-international-society-for-biophysical-economics-en-montana-junio-de-2017/. 
solo socioculturales y político-económicos. Los organismos que han evolucionado en la biosfera terrestre tienden a expandirse en los hábitats accesibles y a consumir los recursos disponibles en ellos, a menos que operen realimentaciones negativas para contenerlos (los feedback loops de la enfermedad, el hambre, la contaminación del propio entorno...). Los seres humanos, adicionalmente, hemos evolucionado como una especie $K$ y eso significa, entre otras cosas, que la selección natural favoreció a aquellos individuos «más inclinados a satisfacer sus necesidades egoístas a corto plazo, ya sea por medios estrictamente competitivos o mediante conducta cooperativa en el endogrupo. Es decir, individuos altamente predispuestos a la 'gratificación instantánea' pueden haber disfrutado de una ventaja competitiva frente a individuos menos agresivos en la expresión de sus demandas materiales. La bien conocida tendencia humana a 'descontar el futuro' [...] ha evolucionado, casi con toda seguridad, por selección natural» (Rees 2010: 4) ${ }^{16}$. Estas adaptaciones disfuncionales del simio averiado que somos

\footnotetext{
${ }^{16}$ En teoría ecológica, la selección $\mathrm{r} / \mathrm{K}$ pretende explicar la forma en la que se seleccionan los rasgos de un organismo de acuerdo con dos grandes estrategias. Las estrategias $r$ favorecen una gran cantidad de descendientes con alta mortalidad infantil y juvenil, sacrificando la inversión parental. Si por el contrario el volumen de la progenie es reducido y así se permite una mayor atención parental, se habla de una estrategia $K$. Por ejemplo, la reproducción de las ballenas sigue una estrategia de selección $\mathrm{K}$, con poca descendencia, gestación larga, un largo periodo de cuidado parental y un periodo largo hasta la madurez sexual. La terminología de la selección r/ K fue acuñada por los ecologistas Robert MacArthur y E. O. Wilson en 1970 a partir de su trabajo sobre biogeografía insular. Obviamente, los seres humanos somos «organismos K».

La teoría sostiene que en entornos inestables o imprevisibles, la selección $\mathrm{r}$ predomina debido al énfasis puesto en una reproducción veloz. En estos ambientes, hay poca ventaja en las adaptaciones que permiten competir exitosamente con otros organismos, porque el entorno probablemente cambiará nuevamente y con frecuencia. Entre los rasgos que se piensa que caracterizan la selección $r$ se encuentran la fecundidad alta, la talla reducida, la llegada temprana de la madurez, tiempo de gestación corto y la capacidad de dispersar su descendencia ampliamente. Frente a ello, «los organismos K-seleccionados exhiben rasgos asociados con la vida en una población cuyo tamaño se acerca a la capacidad de carga del ecosistema, y típicamente son competidores fuertes en nichos ocupados, que invierten más recursos en menos descendientes, cada uno de los cuales tiene una probabilidad relativamente alta de sobrevivir hasta la edad adulta (baja tasa de crecimiento r, y una población cercana a la capacidad de carga K). En la literatura científica, las especies $\mathrm{r}$-seleccionadas son ocasionalmente identificadas como 'oportunistas' mientras que las especies K-seleccionadas son descritas como 'de equilibrio'» (voz «Teoría de la selección r/K» en Wikipedia). La terminología de la selección r/K fue acuñada por los ecólogos Robert MacArthur y E. O. Wilson en 1970 a partir de su trabajo sobre biogeografía insular.
} 
engranan luego con las disfuncionales estructuras socioeconómicas y el disfuncional paradigma cultural del capitalismo fosilista.

\section{INTELIGENCIA COLECTIVA, CREACIÓN ÉTICO-POLÍTICA}

Pero ese casi de «casi todas las circunstancias» resulta crucial: la diferencia entre poco y nada sobre la que he llamado la atención tantas veces ${ }^{17}$.

Cabe pensar que lo que estaba intentando en la toma de conciencia ecológica de los años sesenta y setenta del siglo XX era precisamente desarrollar ese pseudópodo (feedback loop) a través del cual la Gran Ameba volviera reflexivamente sobre sí misma... Un proceso que fue trágicamente desbaratado por el neoliberalismo triunfante a partir de los años ochenta, pero que no necesariamente tenía que fracasar.

La izquierda no debería quedar entrampada en los debates sobre sociobiología de los años setenta del siglo XX ni cegarse ante la evidencia de que, si somos animales producto de la evolución biológica, los factores que gobiernan dicha evolución tendrán algún efecto sobre el desarrollo humano. ¿Está la insostenibilidad en nuestra naturaleza? La insostenibilidad podría ser una propiedad emergente de la interacción sistémica entre los sistemas humanos actuales (capitalismo fosilista para abreviar) y la biosfera, como sugiere William Rees (Rees 2010: 3).

\footnotetext{
${ }^{17}$ Esta sería también la posición de Carlos de Castro: «La Ameba determina bastante, casi totalmente, que los individuos se comporten 'amébicamente', pese a que eso nos conduzca al suicidio colectivo. Las masas no son tan culpables como las élites (que tampoco tienen cerebro), pero son también partícipes más o menos conscientes (impotentes las más, pero partícipes). No olvidemos tampoco que en psicología y sociología abundan las 'trampas sociales': comportamientos colectivos estúpidos (todos pierden) [a partir de la composición de las acciones de] individuos inteligentes [...]. Lo que nos dice la historia (Gimbutas, a quien citan Paco Puche y Jordi Pigem, así como también la Ayuda mutua de Kropotkin y En la espiral de la energía de Luis González Reyes y Ramón Fernández Durán) es que han existido sociedades aceptablemente complejas sin graves conflictos internos y sin graves conflictos con el entorno ecológico (y si desaparecieron fue por la invasión de civilizaciones violentas o por catástrofes ecológicas). Eso es bueno y da optimismo. Lo que no es bueno es que la Ameba no tiene solución ya, el colapso es inevitable, precisamente porque en conjunto somos Ameba y una Ameba no puede dejar de ser tal, no se puede transformar una Ameba en Homo sapiens en cincuenta años» (comunicación personal, 18 de abril de 2017).
} 
Hay que añadir enseguida: no hay rasgo de la conducta humana que no esté potencialmente sometido a control cultural... De ahí la importancia de la creación ético-politica (asunto sobre el cual, con toda razón, insistió hasta la extenuación el filósofo greco-francés Cornelius Castoriadis). Dado que nuestra naturaleza biológica es intrínsecamente cultural, una tendencia humana con bases biológicas no supone una inevitabilidad. Pero -eso sí- para ser quizá capaces de controlar tal tendencia hemos de comenzar por reconocerla, por identificarla. Como el científico de sistemas Stafford Beer señaló, «no podemos regular nuestra interacción con ningún aspecto de la realidad que no esté incluido en nuestro modelo de la realidad» (Beer 1981).

La inteligencia colectiva no es un asunto de mejor software y más potencia de cálculo, sino de dar poder a instituciones bien diseñadas que permitan y alienten la deliberación racional (como los «jurados ciudadanos» por ejemplo $)^{18}$. La rica literatura sobre democracia deliberativa, a lo largo de los últimos tres decenios, nos ilustra lo suficiente al respecto (una síntesis inspiradora en Van Reybrouck 2017, capítulo 4). ¡Las mismas personas, bajo reglas de juego

\footnotetext{
${ }^{18}$ Robert Dahl, por ejemplo, ha propuesto la institución del minipopulus: un comité de unos mil ciudadanos y ciudadanas elegidos al azar, conectados mediante telecomunicaciones y asesorados por expertos y estudiosos, cuya tarea consistiría en deliberar durante cierto tiempo (seis meses, un año) sobre una cuestión de particular importancia para la comunidad. No sustituiría a las instituciones representativas, sino que las complementaría. Los juicios del minipopulus representarían a los de la ciudadanía de una comunidad democrática: su veredicto sería el de la comunidad de ciudadanos y ciudadanas, si esta estuviese en condiciones de aprovechar los mejores conocimientos disponibles para resolver qué políticas pueden con más probabilidad llevarla hacia los fines que persigue (Dahl 1992: 408).

Una idea parecida se ha materializado en experiencias ejemplares en algunos países. Los anglosajones lo llaman consensus conferences, conferencias de consenso o tribunales de ciudadanos (véase al respecto Moreno Muñoz / Iáñez Pareja 1997: 309-311): un grupo no demasiado extenso de ciudadanos y ciudadanas escogidos al azar (cuidando su representatividad) reciben durante cierto tiempo información básica sobre una cuestión políticamente relevante (por ejemplo, la manipulación genética). Luego se reúnen en un seminario de tres días: en el primero oyen el testimonio de expertos a favor y en contra de la actividad que se debate, en el segundo interrogan a los expertos (y hacen que estos se interroguen entre sí), y en el tercero deliberan y elaboran un informe final de conclusiones. En países de mayor sustancia democrática que el nuestro, como Dinamarca, se han celebrado decenas de estas conferencias de ciudadanos, organizadas por el Departamento de Tecnología de Dinamarca (se celebraron, por ejemplo, conferencias sobre biotecnología agrícola e industrial en 1987, sobre irradiación de productos alimenticios en 1989, sobre manipulación genética de animales en $1992 \ldots)$.
} 
diferentes (instituciones mejores o peores), adoptan decisiones distintas! Más o menos egoístas, más o menos suicidas, más o menos atentas al bien común...

La política es el arte de crear los contextos donde las personas puedan dar lo mejor de sí mismas. Toda la cuestión del desarrollo humano se sintetiza en un bucle de realimentación (el pseudópodo de la Gran Ameba) que, naciendo en ese "centauro ontológico» que es el ser humano (Ortega dixit), vuelve al mismo y le dice: potencia lo mejor de ti mismo. No te dejes caer a tus peores posibilidades...

\section{ANTROPOCENO + CAPITALOCENO}

Podríamos concluir entonces (justificando el título que elegí para estas páginas): necesitamos el concepto crítico del Capitaloceno, formulado desde las ciencias humanas y la filosofía, para no perder de vista los mecanismos causales esenciales (la valorización del valor impulsora de la dinámica autoexpansiva del capital) que están detrás de la fenomenal crisis ecosocial planetaria a que hacemos frente (y orientar los posibles intentos de salida); pero, al mismo tiempo, deberíamos ser capaces de reconocer que tenemos también un problema antropológico de fondo -y por eso conservar igualmente, no solo desde la geología sino también desde las ciencias humanas y la filosofía, el concepto de Antropoceno. Ahí ya no como una noción descriptiva, sino también como concepto crítico. Crítico, entre otros factores, del disfuncional antropocentrismo que constituye una de las principales raíces culturales de la presente crisis. 


\section{REFERENCIAS BIBLIOGRÁFICAS}

AgUADO, Mateo (2016a): Vivir bien en un planeta finito. Una mirada socio-ecológica al concepto de bienestar humano. Tese de doutoramento defendida no Departamento de Ecoloxía, Universidad Autónoma de Madrid, 17 de marzo de 2016.

Aguado, Mateo (2016b): «Llamando a las puertas del Antropoceno», Repensando las relaciones naturaleza-sociedad en un planeta finito (número monográfico), Iberoamérica social: Revista-red de estudios sociales, VII, 41-49 (http://iberoamericasocial.com/llamando-las-puertas-del-antropoceno/) [última consulta: novembro de 2018].

Alonso Millán, Jesús (1995): Una tierra abierta. Materiales para una historia ecológica de España, Madrid, Compañía Literaria.

BALIBAR, Étienne (1990): «Droits de l'homme et droits du citoyen: la dialectique moderne de l'égalité et de la liberté», Actuel Marx, 8, 13-32.

BARBA, Juan Carlos (2017): «Es imprescindible dejar de pensar en el crecimiento económico», El Confidencial, 21 de abril de 2017 (http://blogs.elconfidencial.com/economia/grafico-de-la-semana/2017-04-21/ dejar-pensar-crecimiento-economico-calentamiento-global_1370039)_[última consulta: novembro de 2018].

BEER, Stafford (1981): «I said, you are Gods», Teilhard Review, 15:3, 1-33.

Bonneuil, Christophe / Jean-Baptiste Fressoz (2013): L'événement anthropocène. La terre, l'histoire et nous, París, Le Seuil.

CANo Ramírez, Omar Ernesto (2017): «Capitaloceno y adaptación elitista», Ecología Política, 53 (http:// www.ecologiapolitica.info/?p=9698) [última consulta: novembro de 2018].

CASTRO, Carlos de (2008): El origen de Gaia, Badajoz, Editorial @becedario.

CATTON, William R. / Riley E. DunLAP (1978): «Environmental sociology: a new paradigm», The American Sociologist, 13, 41-49.

Crutzen, Paul J. / Eugene F. Stoermer (2000): «The Anthropocene», Global Change Newsletter, 41, $17-18$.

DAHL, Robert (1992): La democracia y sus criticos, Barcelona, Paidós.

DUARTE, Carlos (coord.) (2006): Cambio global. Impacto de la actividad humana sobre el sistema Tierra, Madrid, CSIC.

ENGELMAN, Robert (2013): «Más allá de la sosteniblabla’», en Worldwatch Institute, La situación del mundo 2013. ¿Es aún posible lograr la sostenibilidad?, Madrid / Barcelona, FUHEM Ecosocial / Icaria Editorial, 27-49.

Fernández Carril, Luis / Andrea Cardoso / Florent MarCellesi (2017): «Editorial», Ecología Política, 53 (número monográfico sobre Antropoceno) (http://www.ecologiapolitica.info/?p=9696) [última consulta: novembro de 2018].

FERNÁNDEZ DURÁn, Ramón (2011): El Antropoceno: la expansión del capitalismo global choca contra la biosfera, Barcelona, Ed. Virus. (Pode descargarse unha versión anterior do libro en http://www.rebelion. org/docs/104656.pdf) [última consulta: novembro de 2018].

García, Ernest (2004): Medio ambiente y sociedad, Madrid, Alianza.

Hagens, Nate (2016): «¿Qué sucedería si los paneles fotovoltaicos fuesen gratuitos?», Crisis energética, 3 outubro de 2016 (http://www.crisisenergetica.org/article.php?story=20161003140431501) [última consulta: novembro de 2018]. 
Harari, Yuval Noah (2016): Homo Deus, Barcelona, Debate.

Herrero, Amaranta (2017): «Navegando por los turbulentos tiempos del Antropoceno», Ecología Política 53, xuño de 2017 (http://www.ecologiapolitica.info/?p=9703) [última consulta: novembro de 2018].

JORGE, Judith de (2015): «Y la humanidad dio la "Gran Aceleración”», $A B C, 15$ de xaneiro de 2015 (http:// www.abc.es/ciencia/20150115/abci-humanidad-gran-aceleracion-201501151521.html) [última consulta: novembro de 2018].

LADANTA LASCANTA (Grupo venezolano ecofeminista de investigación e acción) (2017): «El Faloceno: redefinir el Antropoceno desde una mirada feminista», Ecología Política, 53, xuño de 2017 (http://www. ecologiapolitica.info/?p=9705) [última consulta: novembro de 2018].

Lovelock, James E. (1986): Gaia -Una nueva visión de la vida sobre la Tierra, Barcelona, Orbis. [O orixinal inglés é de 1979 e está publicado por Oxford University Press].

MALM, Andreas (2015): «The Anthropocene Myth», Jacobin (http://www.jacobinmag.com/2015/03/ anthropocene-capitalism-climate-change/) [última consulta: novembro de 2018].

Margulis, Lynn (2002): Planeta simbiótico, Madrid, Debate.

Moore, Jason W. (2015): Capitalism and the Web of Life, Londres / Nova York, Verso.

Moore, Jason W. (ed.) (2016): Anthropocene Or Capitalocene?: Nature, History, and the Crisis of Capitalism, Oakland (California), PM Press.

Moore, Jason W. (2017): «Del Capitaloceno a una nueva política ontológica», Ecología Politica 53, Barcelona, xuño de 2017 (http://www.ecologiapolitica.info/?p=9795) [última consulta: novembro de 2018].

Moreno Muñoz, Miguel / Enrique Iáñez Pareja (1997): «Elementos para la resolución de controversias en el debate sobre biotecnología y sociedad», en F. Javier Rodríguez Alcázar / Rosa Ma Medina Doménech / Jesús A. Sánchez Cazorla (coords.), Ciencia, tecnología y sociedad: contribuciones para una cultura de la paz, Granada, Universidad de Granada.

OXFAM (2015): «La desigualdad extrema de las emisiones de carbono». Nota informativa do 2 de decembro de 2015 (https://www.oxfam.org/es/informes/la-desigualdad-extrema-de-las-emisiones-de-carbono) [última consulta: novembro de 2018].

PRAT, Narcís (2017): «El Antropoceno y el futuro de la biosfera», La maleta de Portbou, 23, Barcelona, maio-xuño de 2017.

REES, William E. (2010): «What's blocking sustainability? Human nature, cognition and denial», Sustainability: Science, Practice \& Policy, 6:2, 13-25 (https://pdfs.semanticscholar.org/71fc/12a7de4bc4999b78e160f3628b0d22312558.pdf) [última consulta: novembro de 2018].

REES, William E. (2017): «What, me worry? Humans are blind to imminent environmental collapse», The Tyee, 16 de novembro de 2017 (https://www.thetyee.ca/Opinion/2017/11/16/humans-blind-imminent-environmental-collapse/) [última consulta: novembro de 2018].

Reybrouck, David van (2017): Contra las elecciones. Cómo salvar la democracia, Barcelona, Taurus.

RIECHMANN, Jorge (2012): Interdependientes y ecodependientes, Barcelona, Proteus.

SAITO, Kohei (2017): «Marx en el Antropoceno: valor, fractura metabólica y dualismo no-cartesiano», Marxismo Crítico, 29 de novembro de 2017 (https://marxismocritico.com/2017/11/29/marx-en-el-antropoceno-valor-fractura-metabolica-y-el-dualismo-no-cartesiano/) [última consulta: novembro de 2018]. 
SchmiTz, Oswald J. (2016): The New Ecology: Rethinking a Science for the Anthropocene, EE. UU., Princeton University Press. [O capítulo $1 \mathrm{da}$ obra pode consultarse en http://press.princeton.edu/chapters/ s10848.pdf].

Soto, Pablo de (2017): «Indagaciones críticas sobre el Antropoceno», Ecología Política, 53, xuño de 2017 (http://www.ecologiapolitica.info/?p=9801) [última consulta: novembro de 2018].

STEFFEN, Will et al. (2011): «The Anthropocene: from global change to planetary stewardship», AMBIO, 40, 739-761.

Steffen, Will / Wendy Broadgate / Lisa Deutsch / Owen Gaffney / Cornelia Ludwig (2015): «The trajectory of the Anthropocene: The Great Acceleration", The Anthropocene Review, 2:1, 81-98 (http:// anr.sagepub.com/content/early/2015/01/08/2053019614564785.abstract, http://anr.sagepub.com/ content/2/1/81) [última consulta: novembro de 2018].

ThOMPSON, William I. (ed.) (1989): Gaia. Implicaciones de la nueva biología, Barcelona, Kairós.

Vernadsky, Vladimir (1945): «The Biosphere and the Noosphere», American Scientist, 33:1, 1-12.

VERNADSKY, Vladimir (1997): La biosfera. Introdución de Ramón Margalef. Madrid, Visor / Fundación Argentaria.

WATERS, Colin N. et al. (2016): «The Anthropocene is functionally and stratigraphically distinct from the Holocene», Science, 351, 6269 (http://science.sciencemag.org/content/351/6269/aad2622) [última consulta: novembro de 2018].

Wilson, Edward O. (2017): Medio planeta. La lucha por las tierras salvajes en la era de la Sexta Extinción, Madrid, Errata Naturae.

XerCavins, Josep (2015): «La Gran Aceleración... ‘ hacia el Gran Colapso?», Other News en español, 11 de febreiro de 2015 (http://www.other-news.info/noticias/2015/02/la-gran-aceleracion-hacia-el-gran-colapso/) [última consulta: novembro de 2018].

ZaLASIEWICZ, J. et al. (2014): «When did the Anthropocene begin? A mid-twentieth century boundary level is stratigraphically optimal», Quaternary International. [Unha síntese deste estudo podemos atopala en Ruiz de Elvira, Malen (2015): «La bomba atómica marca una nueva era geológica», Público, 27 de xaneiro de 2015 (http://www.publico.es/ciencias/bomba-atomica-marca-nueva-geologica.html)] [última consulta: novembro de 2018]. 